\title{
Structure of Demersal Fish Community in the South China Sea
}

\author{
Kohei Kihara and Chokei Itosu*1 \\ (Received November 14, 1988)
}

\begin{abstract}
A demersal fish community off Viet Nam was examined in order to know its structure in the tropics. Data were collected by a bottom trawler from December 1968 to July 1969. Analyses were made by data for three seasons from winter to summer. Quantitatively dominant fishes were lizardfish, snapper, Japanese butterfish in winter, and were snapper, lizardfish and bigeye in spring and summer. Spatially dominant fishes were lizardfish and cuttle fish in three seasons, and was bigeye in summer. These fishes are supposed to be core fishes of recurrent groups. Few fishes coexisted with others through the three seasons. Most fishes lived independently.
\end{abstract}

Community organization comprising many species is formed by their biological responses to environmental stresses in the biota-biotope system. The dynamics of species interactions is considered to be influenced not only by individual physiological requirements but also by the abiotic environmental factors. Prior studies have dedescribed variations of demersal fish community structures corresponding with fluctuations in the abiotic environmental factors. ${ }^{1-5}$ )

The objective of this study is to examine structure of demersal fish community in the tropics. An area off Viet Nam in the Sunda continental shelf was selected for the study. In this area a southwest current is induced by monsoon in winter and a northwest current predominate in summer. ${ }^{6}$ )

\section{Materials and Methods}

Biological data were collected by a stern trawler Kyoshin-maru No. 52 (311.8 GT) in three periods between the 20th of December 1968 and the 18th of July 1969 on the Sunda shelf.*2 The number of successful trawl stations was 204 in winter from the 20th of December 1968 to the 26th of February 1969. The number was 216 in spring from the 28th of February 1969 to the 9th of May 1969. The trawl survey was successfully carried out at 205 stations in summer from the 10th of May to the 18th of July 1969. Locations of these stations are shown in Fig. 1.

The trawl net was composed of two seams. The smallest mesh size of the net was $40 \mathrm{~mm}$. The

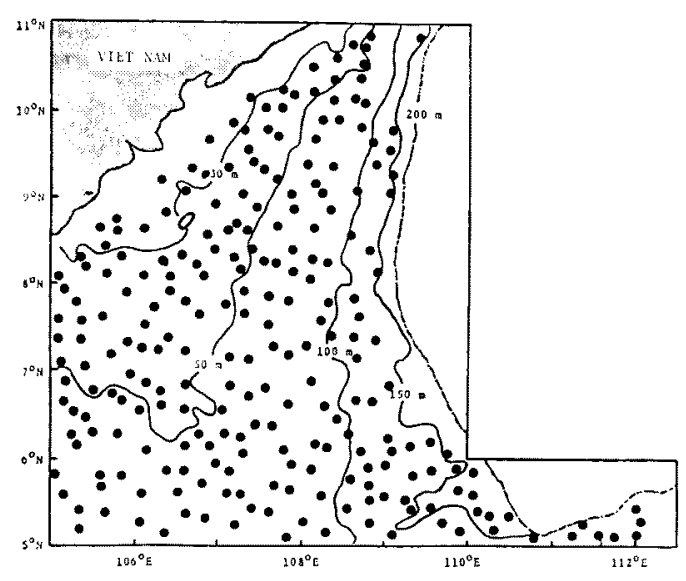

Fig. 1. Survey area and major trawling stations where sampling was repeated in the following three durations: from December 20th 1968 to February 26th 1969, from February 28th to May 9th, and from May 10th to July 18th 1969.

length of the head rope was $36.1 \mathrm{~m}$. Bottom tows of $30 \mathrm{~min}-2$ hours duration were conducted at each station.*2

Biological analyses were made on the fishes which were collected in these surveys (Table 1). An affinity index $(I)$ was calculated to characterize the degree of coexistence among these fishes by the method of Fager. ${ }^{78}$ ) This index is expressed by the geometric mean of the proportion of joint occurrence corrected for sample size:

$$
I=\left[J /\left(N_{a} N_{b}\right)^{1 / 2}\right]-1 / 2\left(N_{b}\right)^{1 / 2}
$$

*1 Department of Marine Science and Technology, Tokyo University of Fisheries, Konan, Minato, Tokyo 108, Japan (木原興平, 系洌長敬: 東京水座大学海洋生産学科).

*2 Kyokuyo Hogei Co., Ltd.: First annual report to FAO of the United Nations on trawling survey in the south China Sea off the Viet-Nam, 1970, pp. 170. 
Table 1. Fish species which were collected in the south China Sea

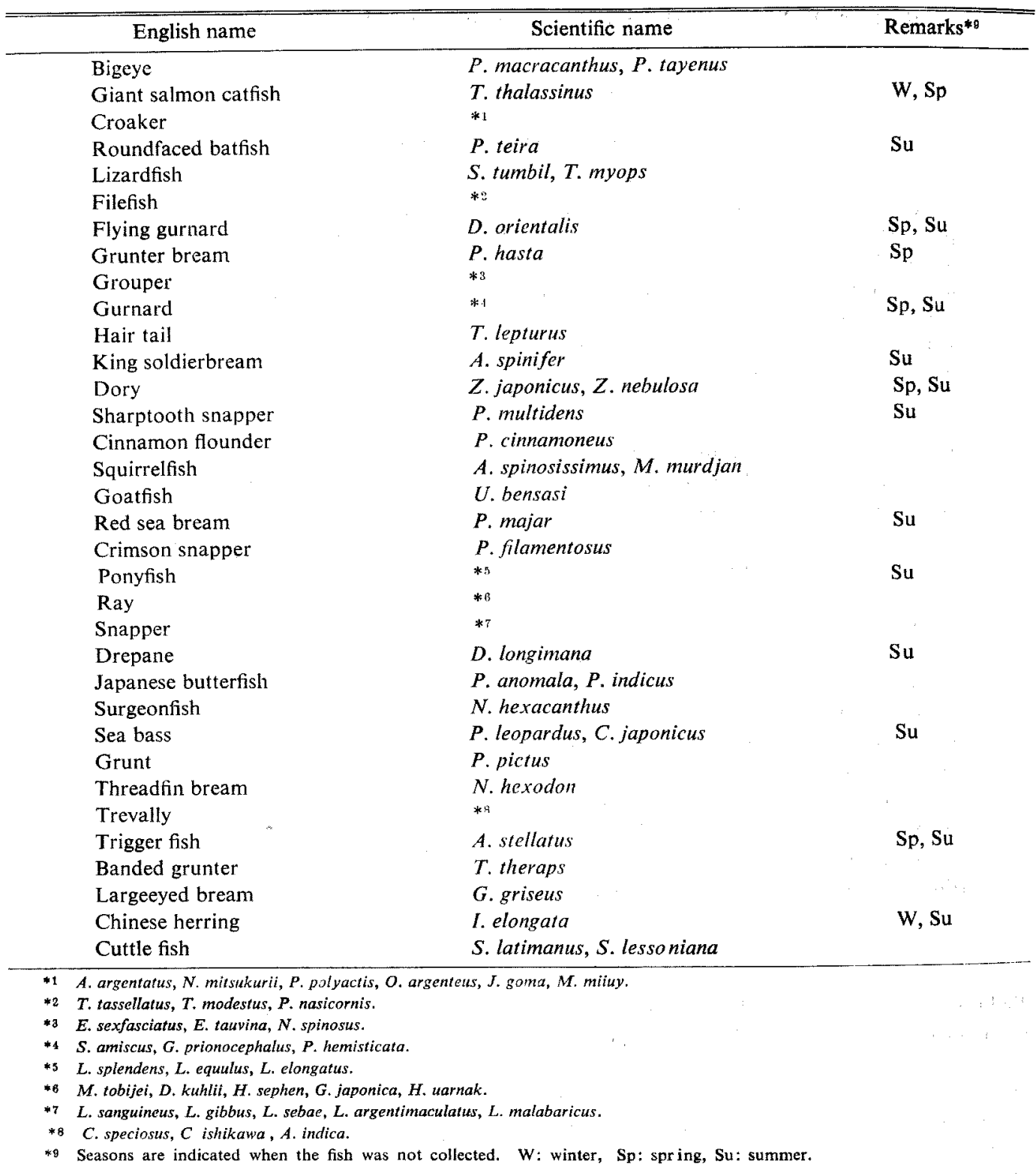

where $J$ is the number of joint occurrences; $N_{a}$ and $N_{b}$ are the total number of occurrences of fishes $\mathbf{A}$ and $\mathbf{B}$ respectively. Fishes are assigned to each letter so that $N_{a} \leq N_{b}$. This grouping is made on the basis of the presence or absence of the fish species. In the present paper, the number of occurrence of each fish is defined as the number of stations where it represents a recorded catch weight of $1 \mathrm{~kg}$ or more. This catch weight is the minimum value of data set. Fishes pairs having the index value equal to or greater than 0.45 were regarded as having a significant affinity with each other. Recurrent groups were then formed according to Fager's requirments that all fishes within a group show significant affinity with all other members of the group, and that each group includes as many fishes as possible. Each fish may not be included in more than one group. These conditions represent groups as the largest, most frequent, separate units within which all inclusive fishes form a constant part of common biological environment. 


\section{Rescults and Discussion}

Species of fishes which were collected through the three seasons were as follows: bigeye, croaker, lizardfish, filefish, grouper, hair tail, cinnamon flounder, squirrelfish, goatfish, crimson snapper, ray, snappear, Japanese butterfish, surgeonfish, grount, threadfin bream, trevally, banded grunter, largeeyed bream and cuttle fish (Table 1). Dominant fishes were lizardfish, snapper, bigeye, Japanese butterfish and cuttle fish.

Flying gurnard, dory, gurnard and trigger fish were collected only in winter. Quantitatively dominant fishes in winter were lizardfish, snapper, Japanese butterfish, bigeye and cuttle fish. Habitats were estimated by the number of stations where fishes were collected in each season. Ratios of the inhabited area of each fish species to the whole survey area in winter: lizardfish $(55 \%)$, cuttle fish $(43 \%)$, snapper $(33 \%)$, and bigeye $(30 \%)$. These fish species were regarded as spatially dominat fishes in this season. The inhabited areas of croaker and ray were narrow. The affinity indices of most fish pairs were not significant in this season. A few fish pairs had significant affinities. Fish pairs having the relatively large indices included, lizardfish and cuttle fish, snapper and largeeyed breeam, and snapper and lizardfish. A community was composed of recurrent groups in winter (Fig. 2). Members of the first recurrent group were bigeye and lizardfish. The second recurrent group was composed of snapper and largeeyed bream. Members of the third group were Japanese butterfish and crimson snapper. Trigger fish and cuttle fish had affinity with one of the two fishes composing the first group respectively. Other fishes did not have any

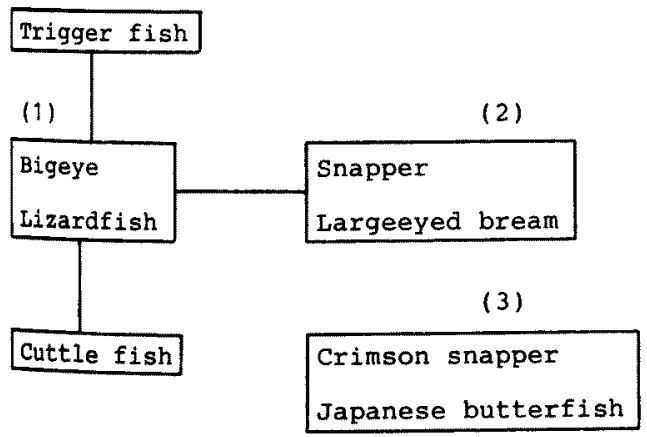

Fig. 2. Structure of demersal fish community in the south China Sea from December 20th 1968 to February 26th 1969. Figures in parentheses are the number of each group.

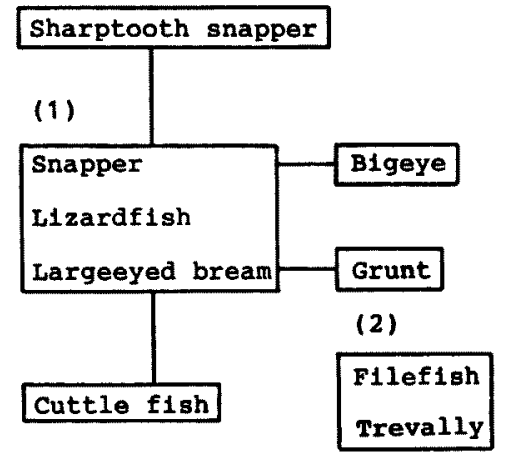

Fig. 3. Structure of demersal fish community in the south China Sea from February 28th to May 9th 1969. Figures in parentheses are the number of each group.

significant affinity. Most other fishes are considered to inhabit independently in winter.

Chinese herring were collected only in spring. Snapper, lizardfish, ray, bigeye, and trevally were quantitatively dominant fishes in spring. Ratios of the inhabited area of each fish species to the whole survey area in spring: lizardfish $(65 \%)$, snapper $(48 \%)$, bigeye $(30 \%)$, cuttle fish $(29 \%)$. These fishes are considered to be dominant spatially. Most fishes did not have so much significant affinity with each other. Fish pairs having significant affinity included, filefish-trevally $(0.70)$, snpper-lizardfish (0.61), sharptooth snapper-largeeyed bream (0.59), snapper-largeeyed bream (0.57), lizardfish-cuttle fish (0.55). A community was composed of recurrent groups as given in Fig. 3. Snapper and largeeyed bream composing the second recurrent group in winter were member of the first recurrent group in spring. Most fishes other than those composing these groups in spring are considered to inhabit independently.

The giant salmon catfish was collected in summer only. Quantitatively dominant fishes in summer were lizardfish, snapper, bigeye, trevally and cuttle fish. Although biological sampling was conducted at a total of 205 stations in this season, ratios of the inhabited area of each fish species to the whole survey area were as follows: bigeye $(74 \%)$, lizardfish $(61 \%)$, cuttle fish $(23 \%)$. These fishes are considered to be dominant spatially. The habitat of threadfin bream was two times as broad as its habitat in spring. A community was composed of recurrent groups shown in Fig. 4. The second recurrent group was independent. That is, fishes composing the group did not have any significant affinity with other fishes. All 


\section{(1)}

Bigeye
Lizardfish
Threadfin bream

(2)

\begin{tabular}{|l|}
\hline Snapper \\
Grunt
\end{tabular}

Fig. 4. Structure of demersal fish community in the south China Sea from May 10th to July 18th 1969. Figures in parentheses are the number of each group.

other fishes than those shown in the Fig. 4 did not have any significant affinity with each other.

The number of fish species was the largest in winter. The habitats of lizardfish and snapper estimated by the number of stations where these fishes were collected were broad through these three seasons. Their habitats were the largest in spring. The habitats of largeeyed bream and grunt showed the same variations as lizardfish. The habitats of bigeye and threadfin bream extended from winter to summer. Cuttle fish and crimson snapper showed an opposite tendency. Catch amount of lizardfish per unit effort was also the largest in these three seasons. Lizardfish was a dominat fish spatially and quantitatively through three seasons. The affinity indices of bigeye and cuttle fish with lizardfish were large and stable from winter to summer. These fishes are supposed to be core fish species of recurrent groups in these three seasons. It is suggested that communities were formed through the changing relationship between these core fish species and fish species such as snapper, threadfin bream, filefish, sharptooth snapper and other fishes which changed the extent of their habitats significantly by season.

This study has elucidated that there were not so many fishes which coexisted with other fishes through these three seasons. Most fishes have inhabited independently. This fact is considered to support that severe competitions among fishes result in less number of coexistence of fishes under a stable environment as in low latitude. ${ }^{8)}$ A further study is necessary to make clear relationships among community structure, its distribution and stability of the marine environment in the tropics.

\section{Acknowledgment}

The authors greatly appreciate the invaluable cooperations of Mr. Noboru Sako.

\section{References}

1) K. Kihara: Nippon Suisan Gakkaishi 49, 41-47 (1983).

2) K. Kihara: Nippon Suisan Gakkaishi 49, 4954 (1983).

3) K. Kihara and A. M. Shimada: Bull. Int. North Pacific Fish. Comm., 47, 31-48 (1986).

4) K. Kihara and A. M. Shimada: Nippon Suisan Gakkaishi, 54, 1131-1135 (1988).

5) K. Kihara and A. M. Shimada: Nippon Suisan Gakkaishi, 54, 2085-2088 (1988).

6) K. Wyrtki: NAGA report, 1961, pp. 1-195.

7) E. W. Fager: Ecology, 38, 586-595 (1957).

8) E. W. Fager: in "The Sea" (ed. by M. N. Hill), Vol. 2, Interscience, London, 1963, pp. 415-437.

9) A. G. Fischer: Evolution, 14, 64-81 (1960). 